\section{OBSTRUÇÃO dAS VIAS AÉREAS SUPERIORES APÓS CATETERIZAÇÃO VENOSA CENTRAL}

Paciente do sexo feminino, 75 anos de idade, deu entrada no pronto-socorro com quadro de dispnéia intensa, cefaléia e sensação de palpitação, com cerca de uma hora de duração. Apresentava antecedentes positivos para miocardiopatia hipertensiva, em uso irregular de inibidores da enzima de conversão e diuréticos, obesidade e diabete tipo II, em uso de hipoglicemiante oral. Ao exame físico, apresentava-se ansiosa, sem déficit neurológico ou rigidez de nuca. Apresentava intenso desconforto respiratório, taquipnéia e estertores crepitantes até terço médio de ambos os campos pulmonares. A oximetria de pulso apresentava uma saturação de oxigênio de 90\%, com máscara de Venturi a 50\%. Recebeu furosemide endovenoso e foi encaminhada para a unidade semi-intensiva, para monitorização e nitroprussiato de sódio por via endovenosa. Após diversas tentativas de cateterizar a veia jugular interna direita, sem sucesso, ocorreu a punção inadvertida da artéria carótida direita, na vigência de uma pressão arterial de 190 x $130 \mathrm{mmHg}$. Realizada a compressão local por 10 minutos. A seguir, foi puncionada a veia subclávia direita por via supraclavicular e introduzido cateter de dupla-via, sem intercorrências. Após a infusão de nitroprussiato de sódio, a pressão arterial foi controlada, com melhora imediata dos sintomas. Entretanto, cerca de 20 minutos após, a paciente iniciou abaulamento progressivo da fossa supraclavicular, e da região cervical e submandibular, com desvio da traquéia para a esquerda, acompanhada da sensação de sufocação, dificuldade de deglutir e falar. Realizada intubação orotraqueal de urgência, por óbvia obstrução de vias aéreas. Na Figura I, observamos a deformidade pelo abaulamento supraclavicular. submandibular e cervical descritos.

Foi realizado mapeamento Duplex da região cervical e supraclavicular que revelou pseudoaneurisma da carótida comum na base do pescoço, com fluxo arterial persistente dentro do hematoma, conforme observado na Figura 2. A seguir, foi realizada compressão do pseudoaneurisma guiada pelo Duplex, por 30 minutos, sob sedação comfentanil, obtendo-se a trombose completa do pseudoaneurisma, como demonstrado na Figura 3.

Após despertar da sedação e apresentan-
Figura I

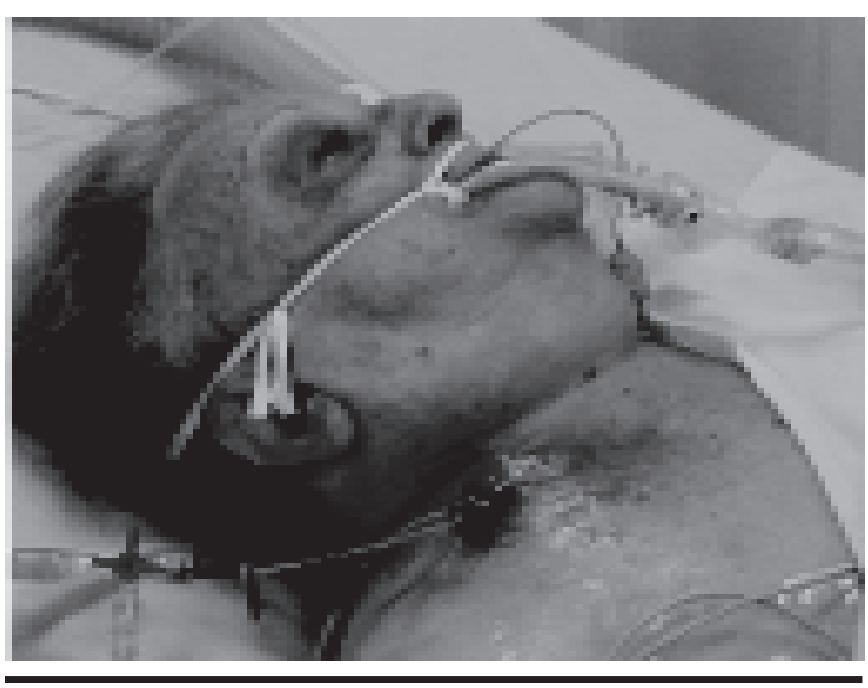

Figura 2

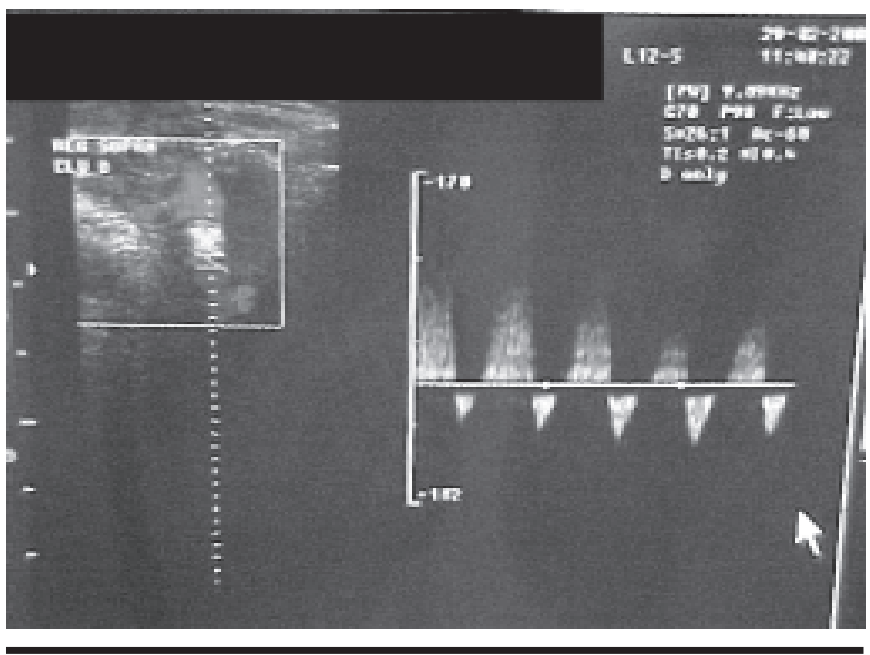

do parâmetros ventilatórios satisfatórios, foi realizada a extubação traqueal. A paciente apresentou novo desconforto respiratório e foi imediatamente reintubada, sem intercorrências. Após três dias de intubação, nova tentativa de retirada do tubo realizada, sob broncoscopia. Entretanto, o exame demonstrou acentuada deformidade posterior da laringe e traquéía, sendo optado pela reintro- 
dução do tubo orotraqueal através do broncoscópio. Persistindo a deformidade da região cervical por mais uma semana, foi optado pela realização de traqueostomia, permitindo a ventilação espontânea. A paciente apresentou boa evolução, com melhora lenta do hematoma cervical e fechamento progressivo da traqueostomia.

\section{Comentário}

Este caso demonstra uma complicação pouco freqüente da punção inadvertida da artéria carótida durante a tentativa de cateterização da veia jugular. Os casos de pseudoaneurismas são mais freqüentes quando a carótida é cateterizada inadvertidamente, principalmente com cateteres calibrosos, como os de Shilley ou de Swan-Ganz. A pressão arterial muito elevada pode ter sido responsável pelo sangramento significativo que, associado a uma compressão local ineficaz, resultou na formação do pseudoaneurisma e na infiltração de sangue pelos planos profundos da região cervical, com obstrução extensa das vias aéreas superiores.
A compressão depseudoaneurisma guiada pelo mapeamento Duplex é o tratamento de escolha para esta condição. É utilizado com grande sucesso, principalmente nos pseudoaneurismas da artéría femoral, após procedimentos endovasculares. Nestes, a hipertensão e agentes antiagregantes e anticoagulantes são fatores predisponentes bem

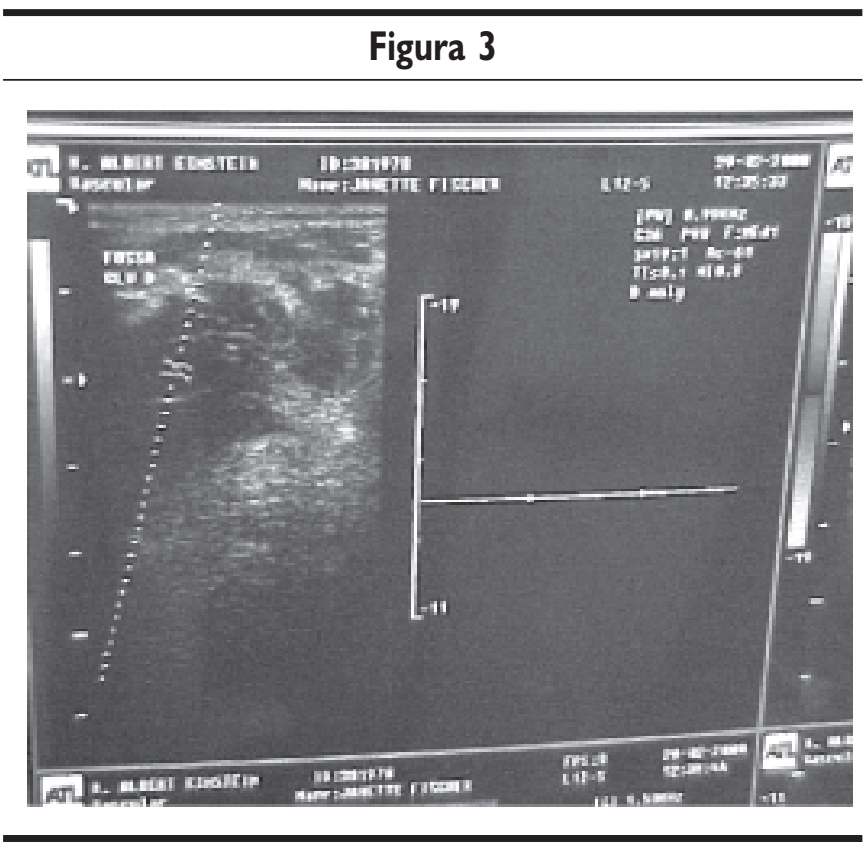
definidos. O tratamento cirúrgico dos pseudoaneurismas fica reservado para os casos em que a compressão não foi bem sucedida. Pseudoaneurismas e fistulas arteriovenosas em locais de dificil acesso, como nos troncos supraaórticos proximais, podem ser tratados de modo muito menos invasivo, através do emprego de endo- próteses pela radiología intervencionista. A retirada do tubo orotraqueal, nestes casos de obstrução mecânica das vias aéreas, deve ser precedido da inspeção pela broncoscopia, evitando-se uma situação potencialmente catastrófica de reintubação dificill.

Luiz francisco Poli de Figueiredo 